\section{Estudo \\ CoDebate}

em Testão

Planejamento
Revista Estudo \& Debate, Lajeado, v. 27, n. 4, 2020. ISSN 1983-036X

DOI: http://dx.doi.org/10.22410/issn.1983-036X.v27i4a2020.2618

\title{
ECOEMPREENDEDORES: ESTUDO DE CASO EM UMA INDÚSTRIA DE MADEIRA PLÁSTICA DO SUL DO BRASIL
}

\author{
Eduardo Herzer ${ }^{1}$, Helena Buzanelo ${ }^{2}$, Mara Cristina Borges ${ }^{3}$, Vanusca Dalosto Jahno ${ }^{4}$
}

\begin{abstract}
Resumo: Para muitos a geração de resíduos sólidos é vista como uma adversidade, já para ecoempreededores essa questáo é encarada como oportunidade de negócio. Com a promulgação da Lei $\mathrm{n}^{\circ} 12.305$ de 2 de agosto de 2010, a qual instituiu a Política Nacional de Resíduos Sólidos, diversas concepções surgiram e se encontram em mudanças contínuas de aperfeiçoamento, uma vez que a lei tem como conceitos a não geração, redução, reutilização e reciclagem dos resíduos antes de uma disposiçáo final adequada, ou seja, o mesmo de reintegrar o ciclo produtivo antes de ser descartado em aterro sanitário. Porém, existem dificuldades ainda neste ciclo, pois faltam projetos e produtos que consigam alcançar a eficiência ambiental e financeira. Uma possibilidade que se mostra promissora é a madeira plástica, na qual pode substituir a madeira natural e demonstra ser econômica e ambientalmente viável. O objetivo desde estudo foi realizar um diagnóstico de como uma indústria de madeira plástica do Vale do Sinos desenvolve suas atividades e, a partir de uma análise técnica, sugerir melhorias nos pontos mais sensíveis encontrados. Em muitos casos, os ecoemprendedores possuem dificuldades em gerenciar o seu negócio deste nicho de mercado. A metodologia foi um estudo de caso dividido em uma pesquisa bibliográfica dos conceitos e uma pesquisa de campo na empresa Alpha localizada no Vale do Sinos. Os resultados apontaram que a empresa requer melhorias a serem desenvolvidas nas áreas do marketing, do controle de qualidade e do acondicionamento de materiais. Os resultados demonstraram que os empreendedores estáo alinhados ao conceito de empreendedorismo e empreendedorismo verde, desenvolver melhorias no seu planejamento, marketing, controle de qualidade e armazenamento em busca da perpetuidade do empreendimento.
\end{abstract}

Palavras-chave: Plásticos. Resíduos sólidos. Negócios Ambientais. Valorização do Resíduo.

\section{ECOENTREPRENEURS: CASE STUDY IN A PLASTIC WOOD INDUSTRY IN SOUTHERN BRAZIL}

\begin{abstract}
For many, the generation of solid waste is seen as an adversity, whereas for eco-entrepreneurs this issue is seen as a business opportunity. With the enactment of Law No. 12,305 of August 2, 2010, which instituted the National Solid Waste Policy, several conceptions emerged and are in continuous changes for
\end{abstract}

1 Tecnólogo em Gestão da Produção e Mestre em Qualidade Ambiental da Universidade Feevale.

2 Arquiteta e Mestra em Qualidade Ambiental da Universidade Feevale.

3 Advogada e Mestra em Qualidade Ambiental da Universidade Feevale.

4 Doutora em Medicina e Ciências da Saúde e Professora do PPGQA da Universidade Feevale. 
improvement, since the law has as its concepts the non-generation, reduction, reuse and recycling of waste before an appropriate final disposal, that is, the same of reintegrating the production cycle before being disposed of in a landfill. However, there are still difficulties in this cycle, as there is a lack of projects and products that manage to achieve environmental and financial efficiency. A promising possibility is plastic wood, in which it can replace natural wood and proves to be economically and environmentally viable. The objective of this study was to make a diagnosis of how a plastic wood industry in Vale do Sinos develops its activities and, based on a technical analysis, suggest improvements in the most sensitive points found. In many cases, eco-entrepreneurs have difficulties in managing their business from this niche market. The methodology was a case study divided into a bibliographic search of the concepts and a field research in the company Alpha located in Vale do Sinos. The results showed that the company requires improvements to be developed in the areas of marketing, quality control and packaging materials. The results showed that the entrepreneurs are aligned with the concept of entrepreneurship and green entrepreneurship, needing to develop improvements in their planning, marketing, quality control and storage in search of the perpetuity of the enterprise.

Keywords: Plastics. Solid waste. Environmental Business. Waste Recovery.

\section{INTRODUÇÃO}

A geração e a disposição de resíduos são um dos grandes desafios da humanidade do século XXI. Conforme a ABRELPE (2019) no ano de 2018 foi gerado mais 216.000 toneladas de resíduos por dia no Brasil, sendo uma geraçáo per capita aproximada de 1,04 kg por habitante/dia no mesmo período. A Política Nacional de Resíduos Sólidos (PNRS) propóe que, antes dos resíduos serem destinados à aterro, deve-se buscar a não geração, redução, reutilização e reciclagem dos resíduos (BRASIL, 2012). Sousa (2012) resalta que a PNRS segue uma tendência mundial que visa a não geração do resíduo, além de definir e delegar funçóes aos agentes envolvidos de forma a buscar a sustentabilidade. Nesta mesma linha Godecke et al., (2012) descrevem que o desejável é que os resíduos sejam reciclados ou reaproveitados e as maiores açôes deveriam estar na não geração e a não disposição final.

Observa-se que o crescimento econômico vem sendo praticado a qualquer custo, esta postura não pode mais ser aceita, pois a sociedade vem exigindo dos empresários, empreendedores e emprendimentos açóes que contribuam para a preservação ambiental e inclusão cidadã, mesmo que os segmentos econômicos tenham como foco a lucratividade conforme aponta Fonseca et al., (2015). Frente a isso surgem as oportunidades de mercado para se empreender em "negócios verdes" (ou ecoempreendimentos). O ecoempreendorismo busca minimizar a degradação ambiental na fabricação de produtos e serviços, onde, além de indetificar e explorar as oportunidades, deve-se criar um valor ambiental com base nos resultado do negócio (SINGH ET AL., 2019).

Dentro da perspectiva do ecoempreendedorismo, os resíduos sólidos podem ser visto como uma oportunidade de negócios. De acordo com Campos et al., (2009) existe uma economia relevante de energia e matéria-prima quando os resíduos são recuperados e reintegrados a um determinado processo produtivo. Porém mesmo que esses emprendimentos trabalhem diretamente com resíduos, os mesmo devem ter preocupaçáo de serem ecologicamente corretos de acordo com as exigências da sociedade e governo, independente do ramo ou tamanho do empreendimento conforme Pinheiro (2011).

Frente a este contexto, o presente estudo tem como objetivo realizar um diagnóstico em uma indústria de madeiras plástica do Vale do Sinos, a partir de um estudo de caso a fim 
de sugerir melhorias nos pontos mais sensíveis encontrados no desenvolvimento das suas atividades industriais e administrativas. De acordo com Bernal-Domínguez et al., (2014) o diagnóstico empresarial busca compreender as atividades do negócio que impactam diretamente no desempenho organizacional e Bruna Junior et al., (2012) complementam que os empreendedores se deparam com desafios característicos desde a criação até as etapas de evolução de tamanho e complexidade do negócio.

\section{REFERENCIAL TEÓRICO}

\subsection{Mercados e Produtos Sustentáveis}

Preservar as futuras geraçóes e suportar os impactos que o ser humano exerce ao longo do tempo do planeta é uma forma responsável de viver, é Ser Sustentável. (OLIVEIRA et al., 2016). E sabe-se que só haverá uma transição para uma sociedade sustentável quando o grau de bem estar for reconhecido por muitas pessoas (VALENTE, 2008). Descrevem que existe uma preocupação crescente em relação ao meio ambiente pelas pessoas, no qual derivam em atitudes favoráveis ao consumo de produtos ambientalmente corretos (NORA; RESENDE, 2011).

Com tudo isso, surge o conceito de consumo sustentável que segundo Silva (2012) consiste em um novo padrão de consumo, onde o direcionado está em alcançar o desenvolvimento sustentável por meio da inter-relação de atores social uma visão política. A luta pela preservaçáo ambiental tem como aliado o consumidor, desta forma existe um enfoque no comportamento do consumidor (PANUCCI-FILHO; HENKES; HENKES, 2018), que possui influencias diretas de variáveis sociológicas, psicossociologia e individuais (CROCCO et al., 2013), Desta forma, o consumidor tende a escolher por produtos que retribua ao conceito que possui ou gostaria de possuir (ELIANE KARSAKLIAN, 2000).

Outro conceito que aponta dentro deste é a dos produtos verdes que por sua vez buscam atender as funçóes básicas dos convencionais, entretanto busca-se mitigar os impactos sobre seu ciclo de vida (MICHAUD; LLERENA 2011). Conforme Enoki et al (2008), estes produtos podem gerar vantagens competitivas para as empresas, através de uma melhoria contínua voltada para o desenvolvimento destes produtos e saindo na frente de seus concorrentes.

\subsection{Madeira Plástica}

A madeira plástica é um produto manufaturado, onde $50 \%$ da sua massa correspondem à plástico, sendo que estes podem ser provenientes de resíduos. Assemelha-se a madeira natural industrializada em seção transversal retangular, podendo ser aplicada em quase toda sua totalidade em setores como a construção civil, agropecuária, moveleiro, empresas de logística (rodoviário e ferroviário) e transmissão de energia elétrica. A produção da madeira plástica ocorre por meio da extrusão de plásticos como o Polietileno de Alta Densidade (PEAD), Polietileno de Baixa Densidade (PEBD), Polietileno Tereftalato (PET), Policloreto de Vinila (PVC), Polipropileno (PP) com agregados como Fibras naturais (OLIVEIRA, 2007; OLIVEIRA, 2005; PAULA \& COSTA, 2008). 
Para Nazário et al., (2016) e Almeida (2013) é evidente que estes produtos auxiliam na preservação ambiental, uma vez que a reutilização de resíduos podem auxiliar na redução da exploração madeireira irregular. Paula \& Silva (2016) descrevem que existe uma resistência por parte das indústrias de transformação de termoplásticos em empregar resíduos de madeiras e outras cargas naturais devido à falta de conhecimento sobres esses. Por outro lado, López \& Rojas (2018) propóem que a produção de madeiras plásticas, compostas a partir de resíduos plásticos e fibras naturais, podem ser uma solução implementada para o manejo adequado destes resíduos.

A madeira plástica tem como vantagem o baixo custo de manutenção, não necessita de recobrimento com tintas e vernizes, apresenta maior resistência à água, mofos e fungos; não apodrece, tem uma durabilidade estimada em até 100 anos, possui um processo limpo de fabricação, pode ser manipulada com as mesmas técnicas de carpintaria e marcenaria da madeira natural, não possui o problema de liberar farpas e rachar, além oferecer conforto térmico. Como desvantagem, pode ser elencado a tecnologia de produçáo pouco acessível e o alto investimento inicial tanto para fabricação, quanto para compra por parte do consumidor final (OLIVEIRA \& COSTA, 2013).

\subsection{Reciclagem}

A reciclagem consiste em um processo, onde um resíduo é incorporado à um processo de produção como matéria-prima ou energia através da reciclagem mecânica, química ou energética. A reciclagem mecânica se caracteriza por reprocessar materiais por meio de pressão e calor com a finalidade de obter outro artefato, através da extrusão, injeção e sopro. No Brasil, esta modalidade de reciclagem vem sendo utilizada principalmente, por questôes de custos e investimentos. Reciclar polímeros na forma de compósitos com fibras naturais é de extrema importância para amenizar os impactos ambientais causados pelo descarte incorreto de resíduos sólidos, além de atrair interesses ambientais e econômicos e ser viável tecnicamente (BONELLI ET AL., 2005; GANDARA \& GONÇALVES, 2017; NAIME, 2004; SPINACÉ \& PAOLI, 2005)

Um dos marcos legais que fomentou a reciclagem, foi em 2010 com a aprovação da Lei Federal 12.305, instituindo a Política Nacional de Resíduos Sólidos (PNRS), a qual trouxe importantes instrumentos e objetivo para a gestão e gerenciamento de resíduos sólidos (BRASIL, 2010). Dentre os quais destaca a reciclagem, quarto item na linha de prioridade trazidas pela PNRS, como importante objetivo na gestão de resíduos, eis que se trata de uma forma de destinação ambientalmente adequada dos resíduos (KELLER; CARDOSO, 2014).

No que tange a legislaçáo estadual e municipal, assiste guarida na PNRS, uma vez que esta instituiu a responsabilidade dos Estados e Municípios na gestão e gerenciamento de resíduos, por meio da elaboração dos planos de gestão e gerenciamento estadual e municipal. Nestes planos, devem constar a responsabilidade compartilhada e logística reversa como forma de incentivar a produçáo de produtos passiveis de reciclar ou reutilizar por meio da. Outro ponto importante citar é o incentivo aos catadores de materiais recicláveis, através do cadastro e organização de cooperativas de catadores, proporcionando a eles inclusão social e econômica dentro das cidades (SOLER, 2016; BRASIL, 2010). 
A reciclagem passou a ser vista não somente como uma aliada ao meio ambiente, mas também como uma oportunidade econômica, possibilitando que produtos antes descartados muitas vezes inadequadamente, sejam reinseridos no ciclo produtivo Ribeiro et al.(2014). Desde 1990 a reciclagem é uma atividade emergente na sociedade brasileira, pois além de aproveitar materiais, possibilita uma dinâmica econômica através da criação de um novo mercado onde exista a geraçáo de emprego e renda. A reciclagem deve ser analisada levando em consideraçáo as particularidades do processamento industrial e de disponibilidade recursos para que se possa apontar com a melhor alternativa viável em uma determinada regiáo (SILVA \& NETO, 2016; WANDERLEY \& ARAUJO, 2018).

\subsection{Empreendedorismo sustentável}

O empreendedor tem a responsabilidade de conduzir o desenvolvimento econômico por meio da criação de novos meios de produçấo, conforme descreve Schumpeter (1934). Paes et al., (2019) complementam que o empreendedorismo gera uma maior produtividade e novas tecnologias de forma a auxiliar no crescimento e desenvolvimento econômico dos países. O empreendedorismo pode ser considerado um estilo de vida, onde as motivaçóes estão em ter satisfação na atividade que se faz, assim gerando um ambiente de satisfação e de harmonia aos clientes de acordo com Bozzo et al., (2019).

Observa-se que o empreendedorismo é oriundo de dois fenômenos, sendo eles: o empreendedor e a oportunidade de mercado, conforme descreve Shane \& Ventakaraman (2000). Silva \& Cunha (1994) destacam que no processo de crescimento empresarial, a busca de oportunidades tem exercido um papel fundamental, e uma destas oportunidade é o que tange e trata sobre sustentabilidade e proteção ambiental. Desta forma, surge o empreendedorismo sustentável que explora oportunidade de negócio relacionas aos nichos social e ambiental e possibilidade de contribuir com a comunidade ou seu ambiente (COHEN \& WINN, 2007; PARRISH, 2010).

De acordo com Delgado et al., (2008), o empreendedor orientado para sustentabilidade deve ter visão de longo prazo para gestáo do negócio estar alinhado a esses princípios de sustentabilidade. Estes são classificados em dois grupos conforme argumento de Parrish (2010), sendo os que sáo os movidos pela oportunidade, onde a sustentabilidade é o meio e os movidos pela sustentabilidade em si, onde a sustentabilidade é o objetivo, de forma que este auxiliem na redução dos impactos e degradação ambiental conforme Singh et al., (2019) Além disso, Borges et al., (2018) explora que o empreendedorismo sustentável pode trabalhar com dois negócios sendo eles o ambiental e o social. Os negócios sociais podem ser produtos para grupos com necessidades especiais, microcrédito, comércio justo e negócios na base da pirâmide e os ambientais são produtos eco eficientes, turismo e lazer na natureza, agricultura orgânica e extrativismo e reciclagem e reutilização (PRAHALAD \& HAMMOND, 2002; LORDKIPANIDZE ET AL., 2005; HOCKERTS $\&$ WÜSTENHAGEN, 2010). Por fim vale ressaltar que são considerados empreendedores sustentáveis aqueles que são motivados ganhos econômicos, sociais e ambientais ou que exploram um determinado nicho de forma a criar valor ambiental ou social em funçáo do seu produto (HOCKERTS \& WÜSTENHAGEN, 2010; PATZELT \& SHEPHERD, 2011). 
Observa-se ainda que não basta ter um espírito de empreendedor sustentável, se faz necessário que o empreendimento desenvolva modelos de negócio condizentes com estes princípios também. Conforme MEIRELLES (2015) a forma como a organização cria, entrega e se apropria de valor se constitui como o seu modelo de negócio. KEEN e QURESHI (2006), destacam ainda o modelo de negócio no contexto da estratégia, uma vez que o modelo de negocio é o "quê" e a estratégia o "como" da inovação dos negócios. Por fim, Joia e Ferreira (2005) descrevem que o modelo de negócio altamente adaptável a realidade das empresas e sendo um instrumento sistêmico e dinâmico de estratégia.

Sendo assim, Joyce et al (2015) destacam que a lógica de criar, entregar, capturar valor econômico, ambiental e social de maneira integrada é definida como modelo de negócio sustentável. Palma et al (2014) descreve que um dos principais desafios aos países em desenvolvimento será constituir modelos de negócios sustentáveis, tornando como fator de vantagem competitiva para as empresas os esforços de redução de impactos socioambientais de produtos e processos. Nota-se que existe uma dificuldade das empresas em visualizar como lucrou e/ou vantagem competitiva as entregas de benefícios socioambientais, pois falta uma abordagem por meio de uma visão holística que atente aos desafios da sustentabilidade e as inovaçôes no modelo de negócio (SCHALTEGGER, LÜDEKE-FREUND, HANSEN, 2011; BOCKEN et al., 2014).

\section{METODOLOGIA}

A pesquisa se caracteriza por ser exploratória, sustentada por uma pesquisa bibliográfica e de campo, com um estudo de caso e abordagem qualitativa. $\mathrm{O}$ estudo de caso consiste em um método de pesquisa intenso, onde se coleta e analisa dados de um sujeito (individuo, comunidade ou grupo), com a finalidade de compreender seu cotidiano, gerando um conhecimento expressivo de um ou mais artefatos (YIN, 2010; GIL, 2012; PRODANOV \& FREITAS, 2013)

O estudo de caso teve como objeto de pesquisa a Empresa Alpha, localizada no Vale do Sinos no Rio Grande de Sul. A Empresa Alpha produz chapas e guias plásticas a partir de resíduos plásticos e fibras naturais. Foi fundada em 2012, contava com um quadro de quatro funcionários e dois sócios e possuía capacidade produtiva de 15 toneladas por mês. A coleta dos dados na empresa ocorreu em outubro de 2017. De forma a operacionalizar o estudo, se adotou o fluxo de pesquisa elucidado na figura 1. 
Figura 1 - Fluxo de pesquisa

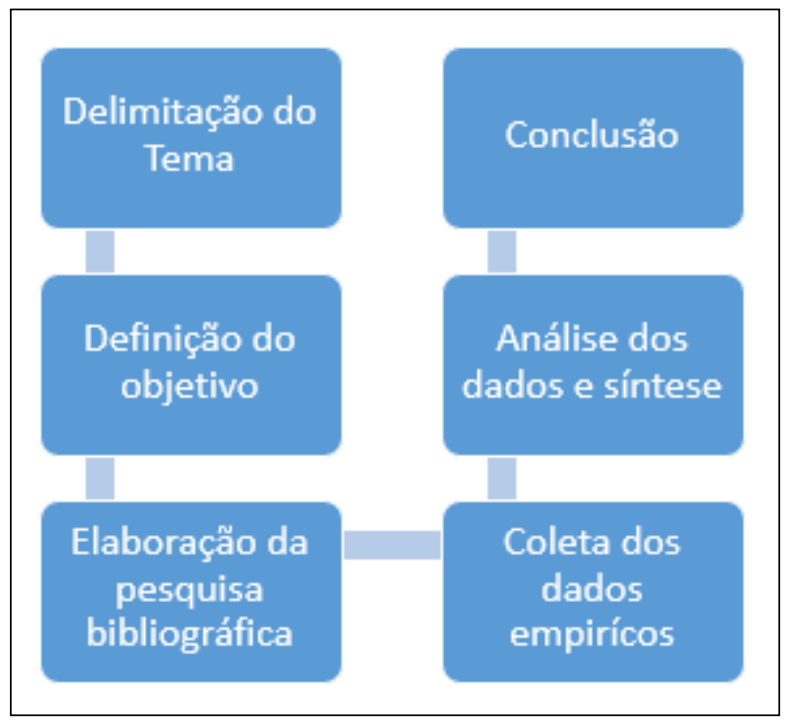

Fonte: Elaborado pelos autores

A delimitação do tema se constituiu na etapa de definir quais conceitos seriam abordados na pesquisa (eco empreendedorismo, madeira plástica, resíduos e reciclagem), o que conduziu à construção do objetivo da pesquisa. Posteriormente, foi elaborada a pesquisa bibliográfica onde foram consultados livros, revistas científicas e dados setoriais para compor o referencial teórico. A coleta dos dados empíricos foi a etapa na qual os dados foram apurados na empresa, onde se utilizou um questionário com 20 itens a serem observados pelos pesquisadores e uma entrevista informal náo estruturada com o empreendedor. A análise das informaçóes ocorreu por meio de uma abordagem qualitativa onde se comparou os dados empíricos coletados com os compilados na pesquisa bibliográfica de forma a encontrar semelhanças e diferenças e propor sugestóes de melhoria.

\section{RESULTADOS E DISCUSSÓES}

A empresa surgiu de uma oportunidade de mercado e da vontade de empreender dos fundadores, movidos pelo sonho de tornar o mundo um lugar melhor. A ideia inicial era desenvolver madeira plástica através da transformação de resíduos plásticos por meio do processo de extrusão. Observa-se que as premissas de Shane \& Ventakaraman (2000) são válidas, uma vez que existia uma vontade de empreender e uma oportunidade de mercado. As premissas de Cohen \& Winn (2007) e Parrish (2010) também são legítimas, pois são exploradas as oportunidades de mercado do nicho ambiental, assim configurando um empreendedorismo sustentável. Nota-se que a empresa possui um viés sustentável desde a sua concepção, na medida em que os empreendedores evidenciaram uma oportunidade de mercado no nicho ambiental, neste caso a madeira plástica, assim também possuindo um modelo de negócio sustentável (MICHAUD; LLERENA 2011). 
No entanto é necessário atentar que transformar em negócios lucrativos as oportunidades identificadas é um dos atributos do empreendedor conforme Valenciano et al., (2005) descrevem. Na busca pela lucratividade a empresa possuía um planejamento estratégico delineado, onde determina como negócio oferecer ao consumidor um produto com qualidade e confiabilidade. A missão descreve que busca através do reaproveitamento de insumo e resíduos de outras empresas, fabricar e comercializar um produto sustentável e inovador de forma a reduzir o consumo de recursos de fontes naturais não renováveis. A visão da empresa era se tornar referência na produção de madeira plástica no âmbito nacional e os princípios estão no pensamento sustentável, respeito e comprometimento. De acordo com Silva et al., (2019) é de vital importância para a organização a existência de um planejamento estratégico para alcançar os objetivos organizacionais, uma vez que acompanha os seus resultados comparando-os com as perspectivas criadas.

Como pode-se evidenciar, no planejamento estratégico da empresa Alpha, existe a premissa da sustentabilidade nos princípios, no negócio e na missão, assim aproveitando as oportunidades que eram descritas por Silva \& Cunha (1994) e validando os dois fenômenos, empreendedor e a oportunidade de mercado, citados por Shane \& Ventakaraman (2000). Além da oportunidade de mercado, vale ressaltar que a captação, elaboração e a avaliação de fatores de viabilidade mercadológica e financeira são de suma importância, pois através deles o empreendedor poderá coordenar planos de açóes por caminhos mais adequados para a abertura e manutenção do empreendimento conforme Santos \& Pinheiro (2017).

Quanto a açóes comerciais, a empresa trabalha com uma estratégia de vendas direta com o consumidor final, por meio de indicação de arquitetos parceiros e através do sistema de busca na internet por parte do consumidor final, ficando restrito a uma atuação regional (Vale dos Sinos/RS). Não se observou nenhuma estratégia sólida de marketing aplicada para atingir a meta de alcançar o mercado nacional assim contrariando a sua visão do planejamento estratégico em ser referência nacional. O marketing é um elemento importante para o empreendedor. Conforme Sparemberger \& Zamberlan (2008, p. 18) "O marketing lida com a identificação e o atendimento das necessidades humanas e sociais. Uma das definiçóes mais sucintas de marketing é atender as necessidades de maneira lucrativa”. Então caberia a empresa mapear as necessidades do mercado nacional quanto a madeira plástica e delinear um plano de marketing tendo como base o composto de marketing: produto, preço, praça e promoção (Kotler \& Keller, 2006). Outra questão a ser levada em consideração são os fatores do consumo sustentável e que seu produto se enquadra como um produto verde e gera vantagem competitiva (ENOKI ET AL 2008; MICHAUD; LLERENA 2011; SILVA, 2012).

Percebe-se que a empresa, para atender sua visão delineada no planejamento estratégico deverá reformular sua estratégia comercial. Kotler \& Keller (2006) descrevem duas fases do marketing, onde a primeira é denominada empreendedora, em que o sujeito argucioso percebe uma oportunidade de mercado e sai de porta em porta para promover o seu produto; e a segunda é a profissional, onde depois de alcançar o sucesso, as pequenas empresas passam a adotar ferramentas de marketing profissionais em seu processo. Como sugestóes, poderia trabalhar com representação comercial em todo a Sul do Brasil e fornecer 
o seu produto em redes de varejo de construção com uma margem menor para atingir seu ponto de equilíbrio de forma mais rápida e a consolidação comercial.

Outro ponto sensível observado visto foi a falta de uma gestão mais efetiva do seu planejamento estratégico. Foi evidenciado que o planejamento é um fator um norteador para a empresa, o que pode ser atribuído pelo dimensionamento de recursos financeiros para a sobrevivência e crescimento do empreendimento. Em relação aos dados e informações contábeis e financeiras, a empresa não abriu cedeu para este estudo em função de questôes de sigilo e estratégia, não sendo possível uma análise mais aprofundada. Contudo, foi possível perceber a dificuldade por meio da fala do empreendedor nas coletas de dados sobre esse assunto. De acordo com Silva \& Pinheiro (2017) pode-se aumentar de maneira significativa a capacidade do negócio responder as demandas locais e reduzir as incertezas das mudanças de mercado e contribui para aumentar a competitividade e sustentabilidade do negócio o fato apenas de planejar. Sugere-se que seja revisado o planejamento estratégico da empresa e redimensionando as necessidades de recursos financeiros da empresa.

Outra oportunidade é exportar o produto para países Europeus e os Estados Unidos, assim promovendo a marca e demostrando ser uma empresa que busca um empreendedorismo sustentável através da percepção das oportunidades no desenvolvimento de produtos e práticas sustentáveis e inovadoras de maneira global conforme Bonfim et al., (2018) destacam. Conforme IYTE (2018) a taxa de crescimento no uso destes produtos na Europa foi de 11\% e 8\% nos Estados Unidos. Conforme SEBRAE (2014) 35\% de pátios e varandas de casas norte americanas já utilizam madeira plástica pela questão de durabilidade e baixa demanda de manutenção e na Europa a utilização destes produtos em decks já é de 47\% (CARUS; EDER, 2015).

Quanto as matérias primas utilizadas na produção, a empresa utiliza polímeros e fibras naturais. Os polímeros utilizados são o $\mathrm{PP}$ e o $\mathrm{PEAD}$ e a fibra natural é a casca de arroz. Os fornecedores são empresas que classificam como resíduo a matéria-prima utilizadas pela empresa, como é o caso empresas de transformação de plásticos da região. Também existe uma representativa parcela de fornecimento de polímeros reciclados por parte das Cooperativas de Catadores da regiáo. A casca de arroz é fornecida por beneficiadoras de arroz do município vizinho de Santo Antônio da Patrulha. Nota-se que a empresa está próxima aos fornecedores uma vez que estão em municípios vizinhos. Desta forma observase que a localização da empresa é estratégica, pois, de acordo com Alves \& Alves (2015) a o local que mais gera benéficos a empresa tal como, melhor nível de serviço ao cliente e redução de custos, caracterizando como localização ideal do negócio.

Quanto ao acondicionamento das matérias-primas, elas ficam estocadas parte em um pavilhão e outra no pátio sem cobertura. A empresa entende a necessidade em não estocar matéria prima ao ar livre por questôes ambientais e alega estar estudando alternativas para solucionar este problema. Conforme Viana (2000) a armazenagem consiste em utilizar o espaço da forma mais eficiente de forma a estocar de maneira prática e respeitando as condiçóes estruturais e regras dos produtos de acondicionamento dos produtos. Sendo assim, a empresa pode melhorar o acondicionamento das matérias-primas em um pavilhão fechado, coberto e com um piso adequado para evitar contaminaçóes de solo e corpos 
hídricos, evitando uma possível paralização da produção caso seja constatado o risco por parte de algum órgáo ambiental, uma vez que a matéria-prima é um resíduo.

Como verificado, as matérias-primas utilizadas pela empresa Alpha são o PP, PEAD e Casca de arroz. O fluxo de produçáo da empresa conta com uma etapa de triagem e separação das matérias-primas, posteriormente uma de moagem das que necessitam, passando pela aglutinação (mistura), seguindo para a extrusão, laminação e expedição como é elucidado na Figura 2. Observa-se também que empresa emprega a tecnologia de extrusão e as algumas das matérias-primas destacadas, por Oliveira (2007), Oliveira (2005) e Paula $\&$ Costa (2008).

Figura 2 - Processo de Fabricação

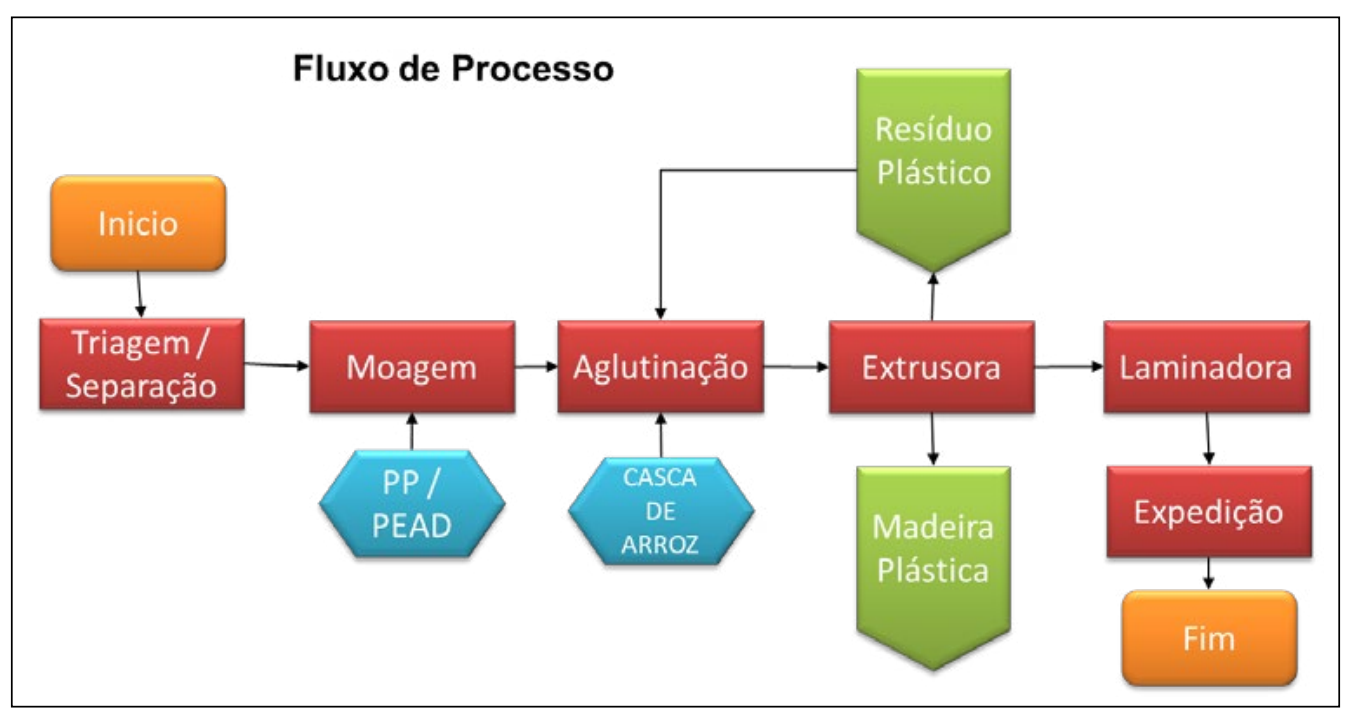

Fonte: Empresa Alpha

Como observa-se na Figura 2, os resíduos do processo de produção (rebarbas e retalhos) são incorporados novamente ao processo de fabricação, de forma a produzir pouco resíduo. Desta forma, se valida o que é postulado por López \& Rojas (2018) que a produção de madeira plástica pode ser uma forma de realizar o manejo adequado de resíduos plasticos e de fibras naturais, uma vez que geram poucos residuos e os mesmos podem ser reintegrados no processo. Esta evidência demonstra que é possivel existir processos industriais menos agressivos ambientalmente e mais eficientes, de forma que a sustentabilidade está na rotina de trabalho de acordo com Orth et al., (2014) e náo estão presente em simples devaneios utópicos e teoricos.

O controle de qualidade ocorre no âmbito visual (cor e textura), sem a realizaçáo de testes de dureza em equipamentos específicos. Conforme Almeida (2013) as análises de propriedade principais são de densidade e de resistência à tração, flexão e ao impacto. Almeida (2013) destaca ainda que, 25\% destas empresas não possuem laboratórios com o maquinário apropriado para realizar os ensaios, assim terceirizando ou estabelecendo parcerias com instituiçóes de pesquisa ou universidades. Outro ponto a ser levantado é uma 
gestão da qualidade sensível, pois não foi evidenciado documentos no qual descrevam as características dos produtos e padróes de processos, de forma a comprometer a qualidade de produtos e serviços aos clientes (OLIVEIRA ET AL., 2011). Sugere-se implantar um sistema de gestão qualidade na empresa para que a mesmo possa promover uma qualidade nos seus produtos e serviços e refletir de forma positiva ao cliente.

A empresa pode formular um plano de investimentos onde tenha como prioridade a aquisição de uma matriz nova para a extrusora, assim viabilizando a fabricação palanques e postes, com a finalidade de ampliar o portfólio de produtos a serem comercializados. Outro item passível de investimento é a implantação de um laboratório com equipamentos para avaliar tecnicamente os lotes produzidos (ou a terceirização deste serviço), garantindo assim a qualidade do produto entregue ao cliente. Assim confirmando o que Oliveira \& Costa (2013) descreve sobre o alto investimento para se adquirir a tecnologia de produção deste produto.

Observa-se que o negócio possui diversos pontos sensíveis a serem tratados, onde alguns requerem investimento financeiro massivo e outros a disponibilidade de criar rotinas, padróes e análises de mercado para que o negócio se sustente financeiramente. Como já visto, o mercado de madeira plástica é promissor a nível mundial, assim se tornando uma alternativa de investimento para futuros empreendedores com viés sustentável.

\section{CONSIDERAÇÓES FINAIS}

Evidencia-se que a empresa requer várias melhorias a serem realizadas a fim de atingir o seu planejamento estratégico, pois existem indícios deste mercado estar em ascensão no âmbito nacional e internacional, já que o produto pode ser utilizado para substituir a madeira natural em grande parte da sua aplicação e exige pouca manutenção. Estes indícios reforçam que a empresa deve explorar melhorias nos seus processos e estruturas para que possa explorar o mercado de forma mais eficiente, produtiva e lucrativa de forma a se consolidar também.

Pode-se notar que a empresa necessita melhorias estruturais tais como no acondicionamento de matérias-primas, implantação de um laboratório de controle da qualidade e uma nova matriz para a sua extrusora. Além das estruturais, existem melhorias de gestáo tais como na sua gestão comercial e de marketing, planejamento estratégico e no controle de qualidade dos materiais que produz. São diversas as melhorias a serem efetuadas pela empresa, as estruturais demandam recursos financeiros, nos quais necessitam ser captados pela empresa, elevando o grau de dificuldade em realizá-las. Contudo as melhorias em gestão que necessitam de recursos financeiros reduzidos e podem ser desenvolvidas o quanto antes por parte do empreendedor, possibilitando captaçáo de recursos através de melhores resultados, e consequentemente, viabilizando as mudanças estruturais.

Evidencia-se que a empresa possui um produto com um potencial de mercado para a venda e ideais alinhados com a premissa do eco empreendedorismo, porém necessita desenvolver melhorias nos seus processos para se consolidar no mercado. A Consolidação no mercado se faz necessário para que o negócio se perpetue e gere resultados econômicos, sociais e ambientais para a sociedade, tais como arrecadação de impostos, reutilização de 
resíduos, redução de impactos ambientais, geração de emprego e renda e retorno sobre o investimento aos empreendedores

O objetivo de realizar um diagnóstico de como uma indústria de madeira plástica do Vale do Sinos-realiza suas atividades foi alcançando, uma vez que se pode conhecer a empresa e constatar os pontos a serem aprimorados, possibilitando sugerir melhorias no processo diante de uma justificativa embasada na literatura técnica pertinente. Observase que estudos desta natureza são importantes, pois buscam trabalhar na identificação e aperfeiçoamentos dos pontos sensíveis da empresa, de forma que possam ser aprimorados para maximizar o resultado da empresa, além de visar uma redução dos impactos ambientais por meio do produto comercializados e suas atividades.

\section{REFERÊNCIAS}

\section{ALMEIDA, A. B. Madeira plástica : estudo da viabilidade técnico e econômico a partir do resíduo sólido Dissertação (Mestrado em Engenharia) - UFRGS 2013.}

ALVES, J. R. X.; ALVES, J. M. Definição de localidade para instalaçăo industrial com o apoio do método de análise hierárquica ( AHP ). Prod. [online], v. 25, n. 1, p. 13-26, 2015.

ASSOCIAÇÃO BRASILEIRA DE EMPRESAS DE LIMPEZA PÚBLICA E RESÍDUOS ESPECIAIS (ABRELPE). Panorama dos resíduos sólidos no Brasil 2018/2019. São Paulo : Associação brasileira de empresas públicas e resíduos especiais, 2016. Disponível em: <http://www.abrelpe.org.br >. Acesso em: nov. 2019

BERNAL DOMÍNGUEZ, D. et al. La alternativa del diagnóstico empresarial para la gestión directiva en las pequeñas empresas comerciales en Sinaloa. Telos: Revista de Estudios Interdisciplinarios en Ciencias Sociales, v. 16, n. 2, p. 278-299, 2014.

BOCKEN, N. M. P. et al. A literature and practice review to develop Sustainable Business Model Archetypes. Journal of Cleaner Production, v. 65, p. 42-56, 2014

BONELLI, C. M. C.; MANO, E. B.; PACHECO, E. B. A. V. Meio ambiente, poluiçáo e reciclagem. São Paulor: Edgar Blücher, 2005.

BONFIM, L. R. C.; VICENTE, A. R. P.; GIMENEZ, F. A. P. Empreendedorismo Sustentável e o Triple Bottom Line: Mapeando a Literatura Internacional. Revista Livre de Sustentabilidade e Empreendedorismo, v. 3, n. 3, p. 158-192, 2018.

BORGES, C. et al. Empreendedorismo Sustentável: Proposição De Uma Tipologia E Sugestôes De Pesquisa. Journal of Chemical Information and Modeling, v. 53, n. 9, p. 1689-1699, 2018.

BOZZO, A. L. et al. Ideologia de vida e motivação empreendedora. RACE - Revista de Administraçáo, Contabilidade e Economia, v. 18, n. 2, p. 281-298, 2019. 
BRASIL. Política Nacional de Resíduos Sólidos, Lei 12.305. Diário Oficial da República Federativa do Brasil, Brasília, DF, 2 ago. 2010. Disponível em: Acesso em: 09.11.2017

BRUNA JUNIOR, E. DELLA et al. Um diagnóstico empresarial sob a perspectiva do ciclo de vida organizacional e comportamento do empreendedor. GEPROS - Gestáo da Produçáo, Operaçóes e Sistemas, v. 7, n. 4, p. 25-41, 2012.

CARUS, M.; EDER, A. WPC/NFC Market Study. 2nova-Institut GmbH, 2015.

CAMPOS, L. et al. A reciclagem como empreendedorismo: Fonte de transformação socioeconômica e ambiental. Revista da Micro e Pequena Empresa, v. 3, n. 1, p. 3-15, 2009.

COHEN, B. .; WINN, M. I. Market imperfections, opportunity and sustainable entrepreneurship. Journal of Business Venturing, v. 22, n. 1, p. 29-49, 2007.

DELGADO, N. A. et al. Empreendedorismo orientado para a sustentabilidade: as inovações no caso da Volkmann. Cadernos EBAPE.BR, v. 6, n. 3, p. 01-21, set. 2008.

\section{ENOKI, P. A. et al. Estratégias de Marketing Verde na Percepção de Compra dos} Consumidores na Grande Sáo Paulo. III Econtro de Marketing da ANPAD - Curitiba 14 a 16 de maio de 2008. Anais...208AD

FONSECA, S. M. M. DA et al. Ecoempreendedorismo E Competências Empreendedoras: O Caso Ecoempreendedor Transformador De Resíduo Em Riqueza. Holos, v. 2, p. 183, 2015.

GANDARA, M.; GONÇALVES, A. R. Compósitos de PET reciclado com fibra de canade-açúcar tratada por explosão a vapor Composites. Revista Matéria, v. 22, n. 4, p. 1-10, 2017.

GIL, A. C. Métodos e técnicas de pesquisa social. São Paulo: Atlas, 2012.

GODECKE, M. V.; NAIME, R. H.; FIGUEIREDO, J. A. S. O Consumismo e a Geração de Resíduos Sólidos Urbanos no Brasil. Rev. Elet. em Gestáo, Educação e Tecnologia Ambiental, v. 8, n. 8, p. 1700-1712, 2012.

HOCKERTS, K.; WÜSTENHAGEN, R. Greening Goliaths versus emerging Davids: theorizing about the role of incumbents and new entrants in sustainable entrepreneurship. Journal of Business Venturing, v. 25, p. 481-492, 2010.

IYTE. D 3.4 Wood plastic composites from recycled hard plastics and wood. 2018

JOIA, L. A.; FERREIRA, S. Modelo de negócios : constructo real ou metáfora de estratégia ? Cad. EBAPE.BR, v. III, n. 4, p. 1-18, 2005. 
JOYCE, A.; PAQUIN, R.; PIGNEUR, Y. The triple layered business model canvas: a took to desing more sustainable business models. Trabalho apresentado no ARTEM Organizational Creativity International Conference, Nancy, França, 2015.

KARSAKLIAN, Eliane. Comportamento do Consumidor. Atlas ed. São Paulo: [s.n]

KELLER, Manoella Miranda; CARDOSO, Waleska Mendes. Destinação dos Resíduos Sólidos Urbanos: breve histórico global e realidade brasileira. In: Semana Acadêmica da FADISMA ENTREMENTES, 2014. Anais... 2014.

KOTLER, P. .; KELLER, K. L. Administração de Marketing. São Paulo: Pearson Prentice Hall, 2006.

LÓPEZ, D. F; ROJAS, A. F. Factores que influencian las propiedades mecánicas, físicas y térmicas de materiales compuestos madero plásticos. Entre ciencia e ingeniería, v. 12, n. 23, p. 93, 2018.

LORDKIPANIDZE, M.; BREZET, H.; BACKMAN, M. The entrepreneurship factor in sustainable tourism development. Journal of Cleaner Production. Journal of Cleaner Production, v. 13, p. 787-798, 2005.

MEIRELLES, D. S. Modelo de Negócio: definições, controvérsias e uma proposta de fundamentação teórica e metodológica. Trabalho apresentado no XXXIX Encontro da ANPAD, Belo Horizonte, 2015.

MICHAUD, Céline; LLERENA, Daniel. Green Consumer Behaviour: an Experimental Analysis of Willingness to Pay for Remanufactured Products.Business Strategy and the Environment, 20, p. 408-420, 2011.

NAIME, R. H. Gestão de resíduos sólidos : uma abordagem prática. Novo Haburgo: Feevale, 2004.

NAZÁRIO, G. F. et al. Madeira Plástica: Uma Revisão Conceitual. Revista Engenharia em Açáo UniToledo, v. 1, n. 1, p. 54-71, 2016.

\section{NORA, E. D. S.; REZENDE, D. C. DE. Marketing Verde e Consumo Consciente:}

Segmentando o Mercado de Lavras/MG. XXXV Econtro da Anpad - Rio de Janeiro - 4 a 7 de setembro de 2011. Anais...2011

OLIVEIRA, M. M. DE et al. Desenvolvimento sustentável nas organizaçóes como oportunidade de novos negócios. Revista Valore, v. 1, n. 1, p. 42-66, 2016.

OLIVEIRA, J. A. DE et al. Um estudo sobre a utilização de sistemas, programas e ferramentas da qualidade em empresas do interior de São Paulo. Produçáo, v. 21, n. 4, p. 708-723, 2011. 
OLIVEIRA, E. M. R. .; COSTA, R. A. Madeira Plástica. Instituto Euvaldo Lodi, 2013.

OLIVEIRA, S. M. Meio Ambiente, Reciclagem e Tratamento de ResíduosTecpar, 2005.

OLIVEIRA, S. M. Madeira PlásticaTecpar, 2007.

ORTH, C. M.; BALDIN, N.; ZANOTELLI, C. T. A geração de resíduos sólidos em um processo produtivo de uma indústria automobilística : uma contribuição para a redução.

Gest. Prod, v. 21, n. 2, p. 447-460, 2014.

PAES, N. N. et al. Determinantes do empreendedorismo no rio grande do sul nicolas. Sinergia - Revista Do Instituto de Ciências Econômicas, Administrativas e Contábeis (ICEAC), v. 23, n. 2, p. 61-70, 2019.

PARRISH, B. D. Sustainability-driven entrepreneurship: principles of organization design. Journal of Business Venturing, v. 25, p. 510-523, 2010.

PATZELT, H.; SHEPHERD, D. A. Recognizing Opportunities for Sustainable Development. Entrepreneurship Theory and Practice, v. 49, n. 0, p. 631-652, 2011.

PALMA, E. P. et al. Estratégias de Negócios Sustentáveis e Desempenho Exportador : uma análise em empresas do setor de gemas e joias. REVISTA BRASILEIRA DE GESTÃO DE NEGÓCIOS, v. 16, n. 50, p. 25-42, 2014.

PANUCCI-FILHO, L.; HENKES, I. DE F. R.; HENKES, J. A. O comportamento do consumidor ecologicamente consciente ainda persiste? Proposição a partir de uma escala validada. R. Gest. Sust. Ambient, v. 7, n. 2, p. 586-612, 2018

PAULA, R. M. DE; COSTA, D. L. Madeira plástica - Aliando tecnologia e sustentabilidade. Encontro Latino Americano de Iniciação Científica. Anais...São José dos Campos: 2008

PAULA, W. F. P. DE; SILVA, L. P. DA. Preparação e caracterização de resíduo pósindustrial de madeira plástica reforçados com resíduos de pó de madeira. Revista Produçáo e Desenvolvimento, v. 2, n. 1, p. 114-124, 2016.

PINHEIRO, F. F. A reciclagem de plástico a partir de conceitos de Produção Mais Limpa. GEPROS - Gestáo da Produção, Operaçóes e Sistemas, n. 3, p. 93, 2011.

PRAHALAD, C. K.; HAMMOND, A. Serving the world's poor, profitably. Harvard Business Review, v. 80, n. 9, p. 48-57, 2002.

PRODANOV, C. C.; FREITAS, E. C. DE. Metodologia do trabalho científico : Métodos e Técnicas da Pesquisa e do Trabalho Acadêmico. [s.l: s.n.]. 
RIBEIRO, Luiz Carlos de Santana; FREITAS, Lucio Flavio da Silva; CARVALHO, Julia Trindade Alves; OLIVEIRA FILHO, João Damásio de. Aspectos econômicos e ambientais da reciclagem: um estudo exploratório nas cooperativas de catadores de material reciclável do Estado do Rio de Janeiro. Nova Economia, Belo Horizonte_24 (1) janeiro-abril de 2014. Disponível em: < http://repositorio.unicamp.br/bitstream/ REPOSIP/87733/1/2-s2.0-84908614857.pdf> Acesso em: 03. Set. 2020.

SANTOS, P. V. S.; PINHEIRO, F. A. O Plano De Negócios Como Ferramenta Estratégica Para O Empreendedor: Um Estudo De Caso. Revista Latino-Americana de Inovação e Engenharia de Produção, v. 5, n. 8, p. 150, 2017.

SANTOS, P. V. S.; Pinheiro F.A. o plano de negócios como ferramenta estratégica para o empreendedor: um estudo de caso. Revista Latino-Americana de Inovação e Engenharia de Produçáo, v. 5. N. 8. P. 150-165, 2017

SEBRAE, Serviço Brasileiro de Apoio às Micro e Pequenas Empresas. Madeira plástica muitas vantagens e inúmeras aplicadades ampliam mercado. Disponível em: https:// respostas.sebrae.com.br/madeira-plastica-muitas-vantagens-e-inumeras-aplicabilidadesampliam-mercado/. Acesso em: 19/08/2020

SCHALTEGGER, S.; LÜDEKE-FREUND, F; HANSEN, E. G. Business Cases for Sustainability and the Role of Business Model Innovation: Developing a Conceptual Framework. Luenesburg: Centre for Sustainability Management (CSM), 2011.

SCHUMPETER, J. A. The theory of economic development; an inquiry into profits, capital, credit, interest, and the business cycle. [s.l.] Harvard University Press, 1934.

SHANE, S. .; VENTAKARAMAN, S. The promise of entrepreneurship as a field of research. Academy of Management Review, v. 25, n. 1, p. 217-226, 2000.

SILVA, A. L. DA; CUNHA, C. J. C. DE A. Busca de oportunidades: o caminho da competitividade. Gestão \& Produção, v. 1, n. 1, p. 89-97, 1994.

SILVA, E. A.; NETO, J. M. M. Possibilidades de melhorias ambientais no processo de reciclagem do polietileno. Polimeros, v. 26, p. 49-54, 2016.

SILVA, L. A. M. DA; PASTOR, C. S.; STÁBILE, S. A importância do planejamento estratégico no ambiente organizacional : um estudo sobre as dificuldades de gestão Administração de Empresas em Revista, v. 19, n. 1, p. 1-16, 2019.

SINGH, A.; ORSIOLLI, T. A. E.; SEGATTO, A. P. Ecoempreendedores e os estágios do ciclo de vida do empreendimento : um estudo de multicasos nos negócios ambientais. REVISTA BRASILEIRA DE GESTÁO DE NEGÓCIOS, v. 21, n. 3, p. 522-539, 2019. 
SOUSA, C. O. M. DE. Política Nacional dos Resíduos Sólidos: uma busca pela a redução dos Resíduos Sólidos Urbanos (RSU). Revista de Saúde, Meio Ambiente e Sustentabilidade, v. 7, n. 3, p. 113-127, 2012.

SOLER, Fabricio Dorado. Os Desafios do Setor Empresarial para a Implementação de Sistemas de Logística Reversa por Intermédio de Acordos Setoriais. In: AMARO, Aurélio Bandeira; VERDUM, Roberto. Política Nacional de Resíduos Sólidos e suas Interfaces com o Espaço Geográfico: entre conquistas e desafios. Porto Alegre: Letra1, 2016, p.31.

SPAREMBERGER, A.; ZAMBERLAN, L. Marketing Estratégico. Ijui: Editora Uniijui, 2008.

SPINACÉ, M. A. DA S.; PAOLI, M. A. DE. A tecnologia da reciclagem de polímeros. Química Nova, v. 28, n. 1, p. 65-72, 2005.

VALENCIANO SENTANIN, L. H.; BARBOZA, R. J. Conceitos de empreendedorismo. Revista Científica Eletônica de Administraçáo, v. 9, 2005.

VALENTE, S. B. M. Luxo Sustentável: a nova estratégia do mercado. X Congresso de Ciências da Comunicação na Região Nordeste - São Luis, MA - 12 a 14 de junho de 2008. Luxo. Anais...2008

VIANA, J. J. Administraçáo de materiais: Um enfoque prático. São Paulo: Atlas, 2000.

WANDERLEY, L. A.; ARAUJO, C. C. DE. Análise Do Setor De Reciclagem No Estado Da Bahia Por Mesorregiōes Entre 2007 E 2015. RDE - Revista de Desenvolvimento Econômico, v. 1, n. 39, p. 1, 2018.

YIN, R. K. Estudo de caso: planejamento e métodos. Porto Alegre: Bookman, 2010. 